\title{
Design of Sectoral Antennas Using a Metallic EBG Structure and Multiple Sources Feeding for Base Station Applications
}

\author{
M. Hajj, E. Rodes, D. Serhal, T. Monédière, and B. Jecko \\ XLIM-UMR CNRS n 6172, Faculté des Sciences et Techniques, 123 avenue Albert Thomas, 87060 Limoges Cedex, France
}

Correspondence should be addressed to M. Hajj, mohamad.hajj@xlim.fr

Received 20 May 2008; Revised 3 October 2008; Accepted 31 December 2008

Recommended by Le-Wei Li

This work aims to study and design base station antennas with metallic electromagnetic band gap (EBG) materials able to create a sectoral radiation pattern presenting at least a $60^{\circ}$ beamwidth. The use of metallic structures offers a new approach to industrial partners seeking to reduce costs and facilitate design procedures. A new method allowing the improvement of both the directivity and the bandwidth by using a printed antenna array is studied.

Copyright (C) 2008 M. Hajj et al. This is an open access article distributed under the Creative Commons Attribution License, which permits unrestricted use, distribution, and reproduction in any medium, provided the original work is properly cited.

\section{INTRODUCTION}

In recent years, a new kind of compact directive antenna has been developed using EBG materials. In these periodic structures, the wave propagation is prohibited for precise frequency bands and defined incidence angles $[1,2]$. The insertion of a defect within the EBG crystal periodicity can create an allowed band inside the forbidden band. It has been shown that by exciting such a structure inside the allowed band, it is possible to design directive antennas able to produce gains as high as $30 \mathrm{~dB}$, thus providing a quasiplanar alternative to the aperture antennas [2-4].

More recently, some structures have been proposed, where the EBG superstrate has been replaced by a metallic partially reflecting surface (PRS). These materials have been used to design different types of antennas with directive [3$6]$ or omnidirectional $[7,8]$ radiation patterns. An example of a directive antenna is given in Figure 1, where the PRS is constituted by a layer of square metallic rods.

Our objective was to obtain a metallic EBG antenna able to create a sectoral radiation pattern presenting a half power beamwidth of at least $60^{\circ}$ in one plane. There are several types of antenna presenting such a pattern, (e.g., antenna arrays) but they require complicated feeding mechanisms. The structure of the sectoral EBG antenna is presented in Section 1 along with the functioning principle. A first design example with experimental results is given in Section 2. An antenna in horizontal polarization designed for uplink
UMTS application [1.92-1.98] GHz with a multisource feeding is presented in Section 3. Finally, another antenna working on the first UMTS band in vertical polarization is introduced and its performances detailed.

\section{PRINCIPLE OF SECTORAL EBG ANTENNA}

The radiation pattern of an EBG antenna being created by a radiating aperture, one only needs to modify the latter properties and shape to obtain the desired form. A sectoral radiation pattern can be obtained by using a rectangular radiating aperture. This can be achieved with an EBG resonator antenna, provided that the energy propagation is impaired in one direction of the azimuth plane. The use of vertical PEC (Figure 2) to limit the energy propagation along the Ox axis results in the desired effect, thus creating the sought after radiation pattern.

The functioning of such a structure is quite similar to a classic rectangular waveguide working on the TE01 mode, except for the energy transmitted through the EBG material. The working frequency of the antenna can thus be obtained through the following relation:

$$
f=\frac{c}{2 \cdot h} \cdot\left(\frac{1}{2}+\frac{\angle E B G}{2 \cdot \pi}\right)
$$

Due to the waveguide-like comportment of the antenna, the $E$ field on the radiating aperture shows no variation along 


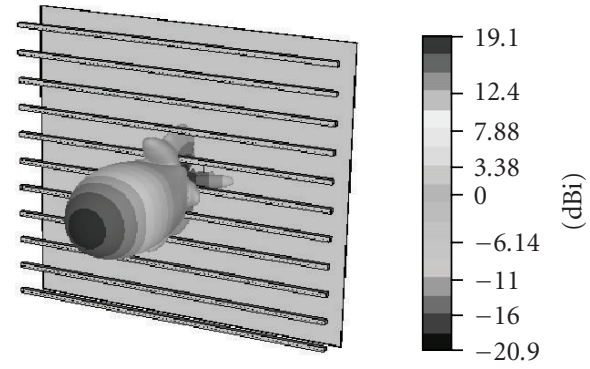

Figure 1: Example of directive EBG antenna.

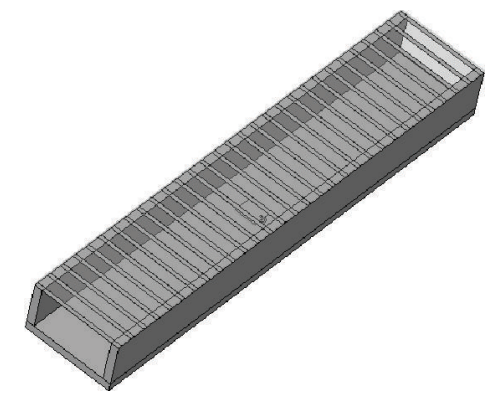

FIGURE 2: Sectoral EBG antenna structure.

the transverse axis (Figure 3). Along the antenna length, an exponential attenuation can be observed as the antenna works under the guide cutoff frequency.

The radiation angle can, therefore, be approximated through the following relation, according to the general theory on rectangular radiating aperture:

$$
\theta=\frac{50.8 * \lambda}{l}
$$

The design of the PRS will then determine the antenna maximum directivity and operating bandwidth, as in the case of more classic directive EBG structures.

\section{FIRST ANTENNA DESIGN AND EXPERIMENTAL VALIDATION}

To illustrate both the principles and the performances of the antennas presented in this paper, a first antenna with $15 \mathrm{dBi}$ directivity and a $60^{\circ}$ beamwidth has been designed. The working frequency corresponds to the first two U-NII frequency bands, that is, $5.15-5.35 \mathrm{GHz}$.

According to the antenna description, its width will directly determine the radiation angle which has to meet the $60^{\circ}$ requirement. The application of the formula given in the previous paragraph yields a value of $47.5 \mathrm{~mm}$, calculated at the upper limit of the frequency band intended for the antenna.

With the antenna width calculated above, $15 \mathrm{dBi}$ directivity requires a $185 \mathrm{~mm}$ length for a rectangular aperture with a uniform field distribution. By considering a 0.8 radiation efficiency factor for the aperture, which is the value usually associated to the EBG resonator structures, a length of

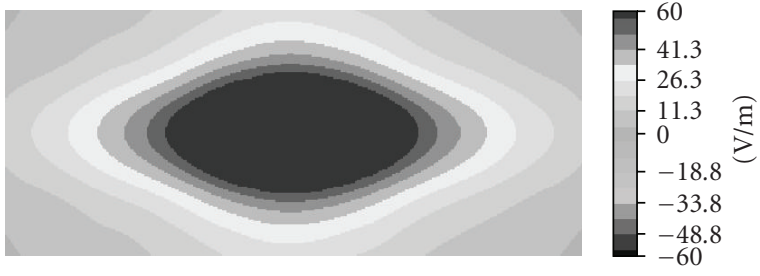

FIGURE 3: Field distribution inside the antenna.

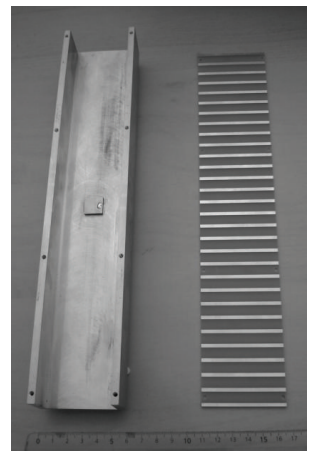

Figure 4: Prototype of the sectoral antenna.

$230 \mathrm{~mm}$ is obtained. The PRS will then be designed to ensure such a length for the radiating aperture.

In order to facilitate the realization of a prototype, an EBG structure composed by a $2 \mathrm{~mm}$ thick FR4 substrate, with metallic lines $2.5 \mathrm{~mm}$ wide printed on it, has been chosen. The reflection coefficient of this structure is $0.91 * \exp$ $\left(\mathrm{j} * 158^{\circ}\right)$ at $5.3 \mathrm{GHz}$, which is compatible with the desired directivity. To obtain an operating frequency consistent with the intended application, the height of the antenna can be determined using the relation (1) which yields a value of $26.6 \mathrm{~mm}$. The final structure, designed with the values previously calculated, is presented in the Figure 4 . The patch antenna used for the excitation of the resonant cavity can be seen in the middle of the picture.

The simulated performances yielded by the antenna in term of directivity and radiation patterns are displayed in Figures 5, 6, and 7. A maximum directivity of $15 \mathrm{~dB}$ has been obtained, which is consistent with the intended values. The radiation angle in the horizontal plane is also correct, being higher than $60^{\circ}$ on the whole frequency band.

Once the prototype realization completed, it has been measured in the anechoic chamber of the XLIM Laboratory, Limoges, France. The radiations patterns are presented in Figures 6 and 7 and compared with the simulation results.

As shown above, the experimental results present a good agreement with the simulated ones, particularly when considering the radiation patterns displayed in Figures 6 and 7. The maximum measured directivity is around $14.5 \mathrm{~dB}$, which corresponds to a $0.5 \mathrm{~dB}$ difference between simulation and experimentation. This discrepancy is caused by the dielectric losses which have been underestimated during the simulation. 


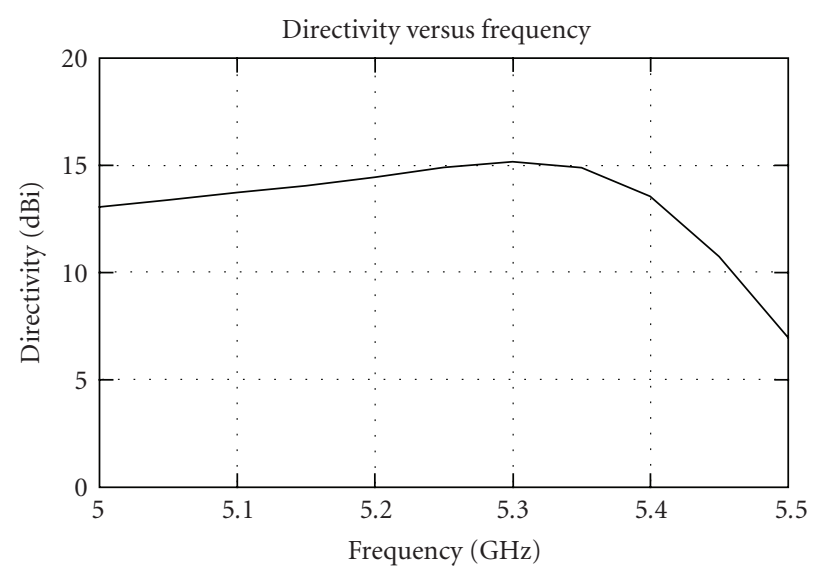

Figure 5: Directivity of the antenna (simulated).

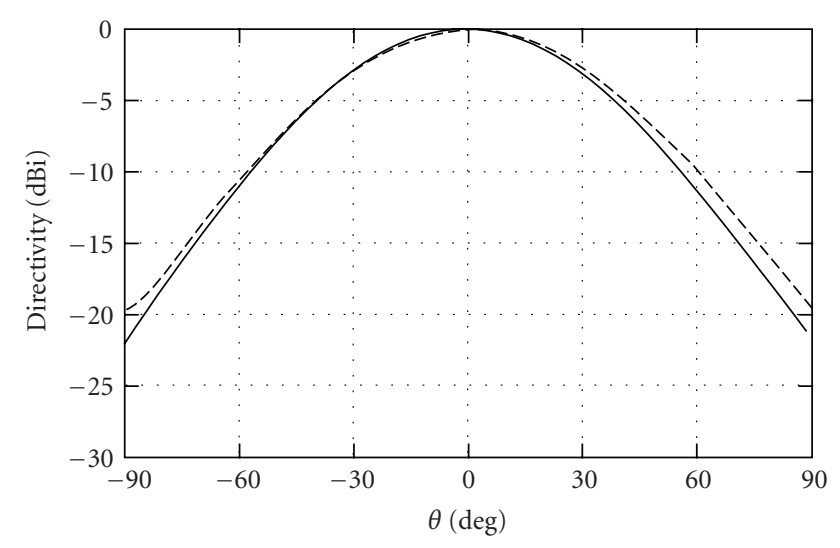

- Simulated

--- Measured

FIGURE 6: Radiation patterns at $5.3 \mathrm{GHz}$ (E-plane).

The principle of the sectoral antenna having been validated by these experimental results, more complicated structure has been studied in order to improve the performances.

\section{STRUCTURE IMPROVEMENT FOR UMTS APPLICATION}

\subsection{Sectoral antenna for a UMTS base station in horizontal polarization}

\subsubsection{Presentation and description}

The new objective is to design an antenna still intended for wireless telecommunication networks base stations but with improved performances. Our sectoral metallic EBG monoband antenna must satisfy the uplink UMTS specifications $(1.92-1.98 \mathrm{GHz})$ [9] with an $18 \mathrm{~dB}$ gain and a radiation beamwidth of at least $60^{\circ}$ in the horizontal plane. This antenna uses only a unidimensional metallic structures working in TE polarization, feed ports and metallic rods must be in a horizontal distribution (Figure 8).

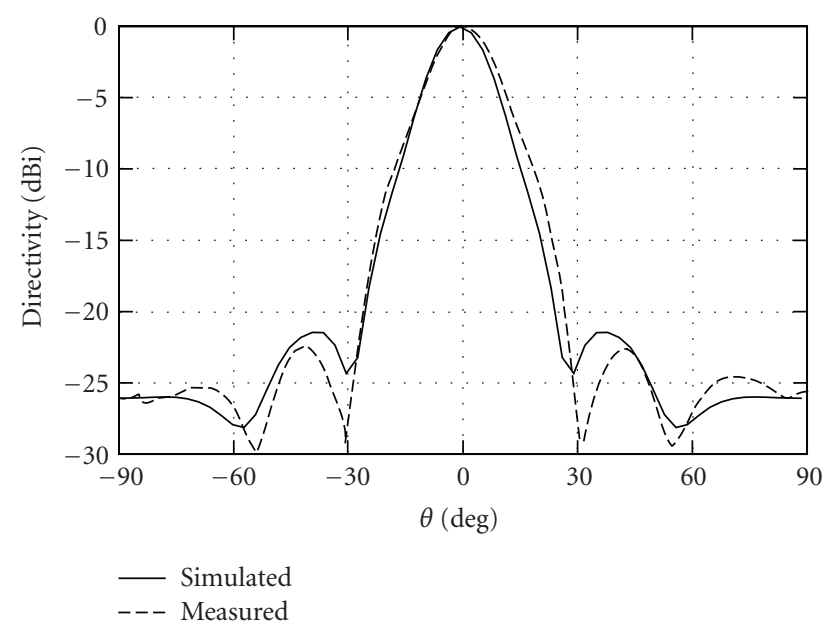

Figure 7: Radiation patterns at 5.3 GHz (H-plane).

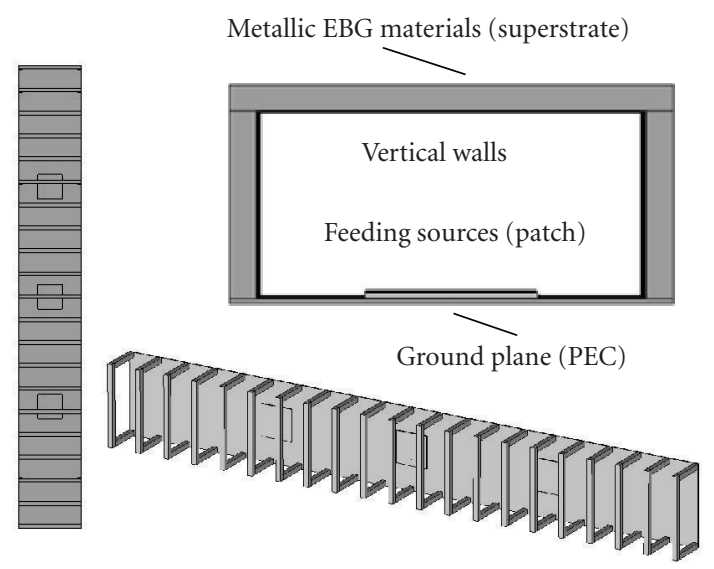

Figure 8: Front, top, and 3D views of the sectoral EBG antenna, monosource case: only the patch in the center is fed, multisource case: three patches are fed simultaneously.

The metallic EBG structure is designed with 21 rods $10 \mathrm{~mm}$ wide in order to regulate the allowed frequency band around $2 \mathrm{GHz}$. The rods period is $60.5 \mathrm{~mm}$ and their thickness is $10 \mathrm{~mm}$. The simulated ground plane has the same size as the structure, that is, $800 * 164 \mathrm{~mm}^{2}$. The antenna cavity height will be determined by the relation (1), where the phases $\angle$ EBG correspond to the reflection coefficient of EBG structure.

The EBG structure is thus situated at $69 \mathrm{~mm}$ over the ground plane, which is about $\lambda_{0} / 2$. Its operating frequency is around $1.96 \mathrm{GHz}$. The vertical walls used in Section 3 are replaced by metallic rods in order to reduce the antenna weight and to facilitate the design.

At the beginning, the antenna directivity with only one feeding source was about $15 \mathrm{dBi}$ with a narrow operating bandwidth. There are several parameters which influence the antenna performances, the filling ratio being one of the most important ones. 


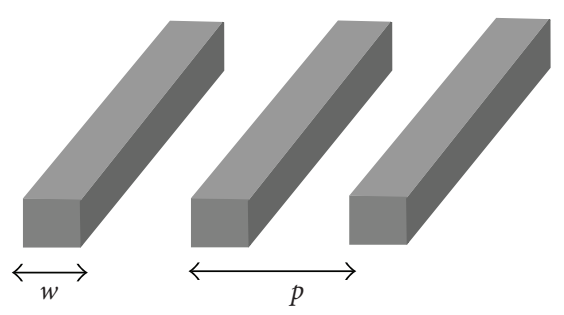

FIGURE 9: $w$ and $p$ values following $\tau$.

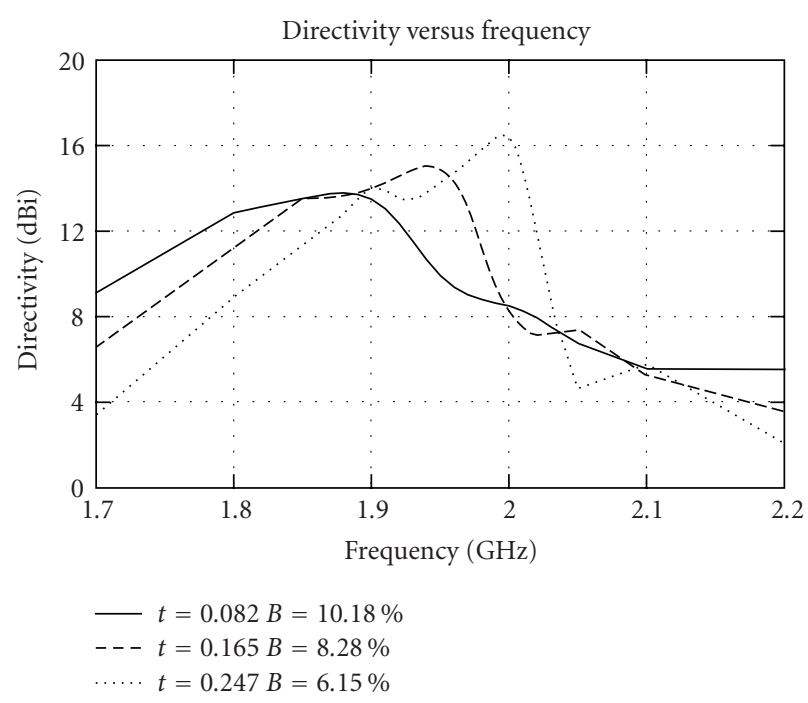

Figure 10: Directivity evolution for the three cases.

\subsubsection{Filling ratio}

The EBG structure is formed by metallic rods that can be dimensioned by considering several parameters like the rods section $(w)$, the rods period $(p)$, in other terms by defining the filling ratio $\tau$, which directly influences the antenna performances (directivity and bandwidth). $w$ and $p$ values are now fixed according to the value of the filling ratio, the latter being defined by (3)

$$
\tau=\frac{w}{p} .
$$

In our case, the PRS structure is composed of 21 metallic rods. Several values of $\tau$ are considered by modifying $w$ and $p$. The following table (Table 1 ) shows the $w$ and $p$ variations related by $\tau$ (Figure 9 ).

Figure 10 presents the directivity variations for different values of the filling ratio.

The curves of figure 10 show that increasing the filling ratio results in an increased directivity increases and a reduced $-3 \mathrm{~dB}$ directivity bandwidth. We can see that this technique is, moreover, insufficient to reach the desired $18 \mathrm{dBi}$ and to obtain the suitable $-3 \mathrm{~dB}$ directivity bandwidth. The multisource technique will, therefore, be used to achieve good results in terms of both directivity and bandwidth.

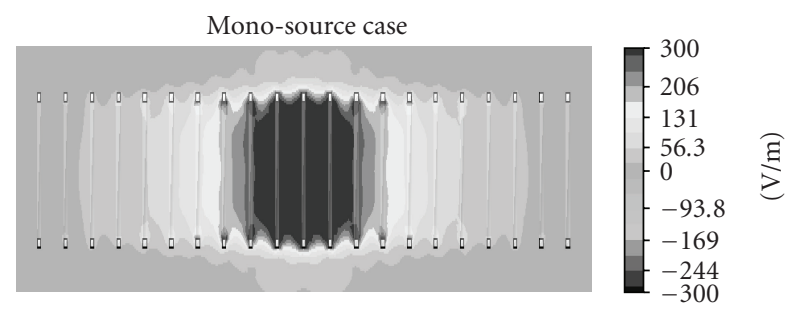

FIGURE 11: Distribution of the tangential electric field module $|\mathrm{Ex}|$.

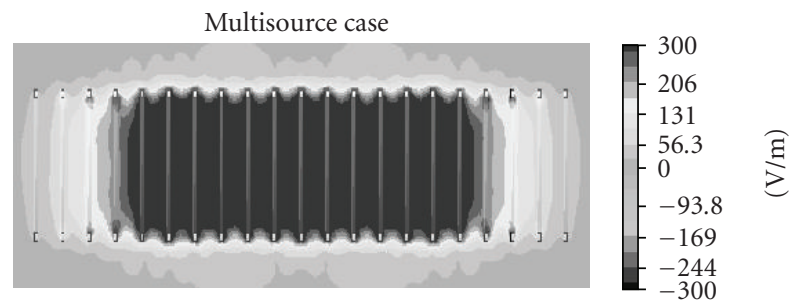

Figure 12: Distribution in the multisource case.

TABLE 1: Different values of $w$ and $p$.

\begin{tabular}{lcc}
\hline & $w(\mathrm{~mm})$ & $p(\mathrm{~mm})$ \\
\hline$\tau=0.082$ & 5 & 60.5 \\
$\tau=0.165$ & 10 & 60.5 \\
$\tau=0.247$ & 15 & 60.5 \\
\hline
\end{tabular}

\subsubsection{Performances enhancement: principle of multisource technique}

The principle of the multiple sources feeding is based on the arrays theory, which can produce an increased directivity by the summation of various elements contributions $[10,11]$. Furthermore, the use of multisource technique enables us to increase the directivity and the $-3 \mathrm{~dB}$ directivity bandwidth simultaneously.

To observe the phenomena, the electric field distribution in a horizontal plane situated in the resonant cavity at the center operating frequency $(1.96 \mathrm{GHz})$ is given for each case (Figures 11 and 12).

The multisource structure presents three sources interspaced by $1.5 \lambda_{0}$ in order to obtain a good apertures interlacement, that is, to obtain quasiconstant field amplitude along the antenna length. Moreover, this dimension of the antenna is extended in order to avoid spillover losses and high side lobes.

\subsubsection{Directivity}

The simulation results of the metallic EBG antenna directivity versus frequency are shown in Figure 13, for the monosource, multisource, and patch only configurations.

The use of the multisource technique enabled us to increase at the same time the gain and the $-3 \mathrm{~dB}$ directivity bandwidth. It is thus noted that this technique can give 


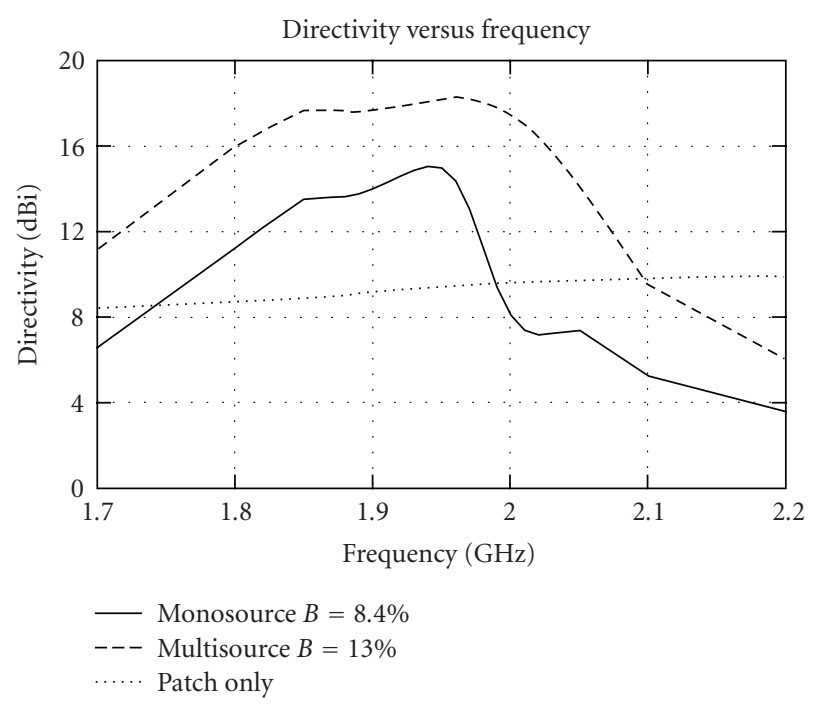

Figure 13: Directivity evolution for the two cases.

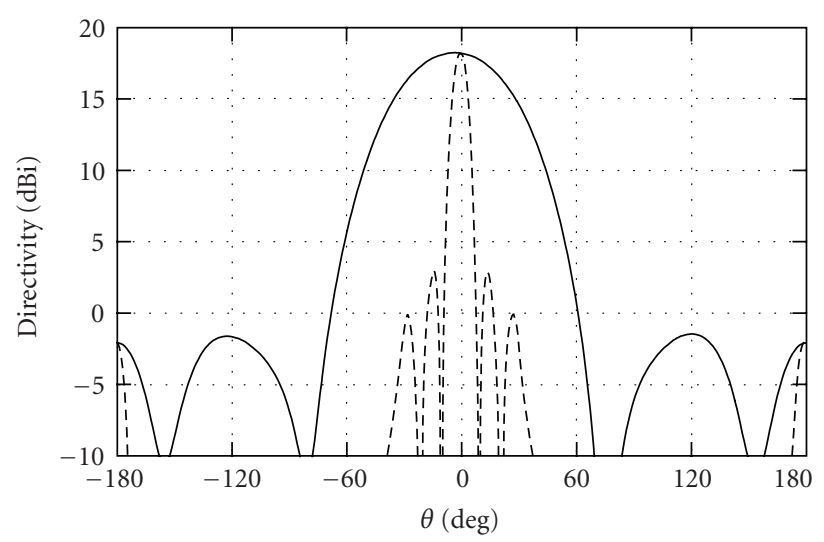

E-plane
--- H-plane

FIGURE 14: Radiation patterns at $1.96 \mathrm{GHz}$

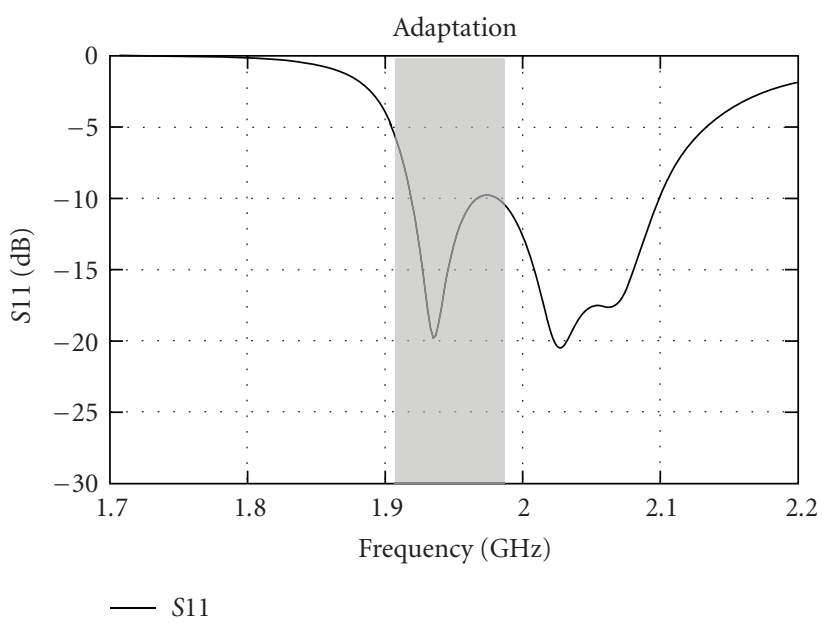

FIGURE 15: Return loss.

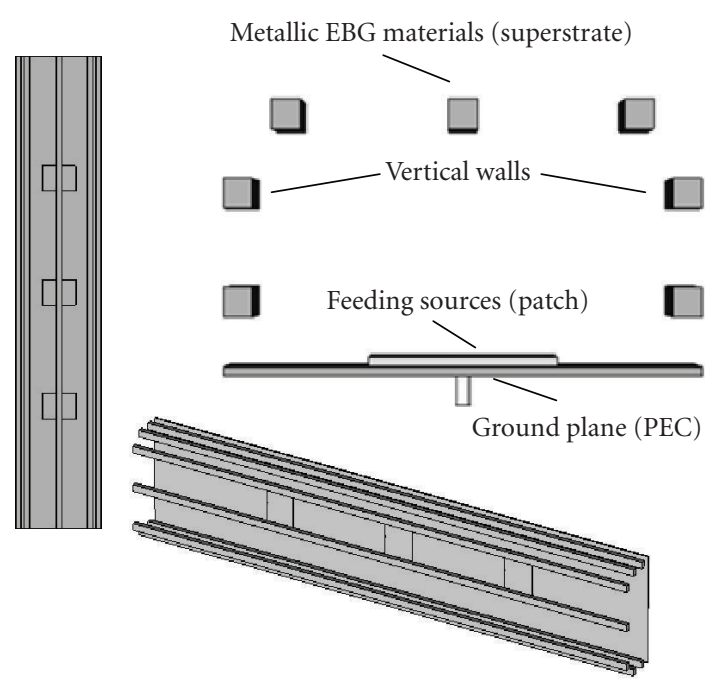

FIgURE 16: Front, top, and 3D views of the sectoral EBG antenna.

very interesting results. Between the two extreme cases, the directivity is increased by $3.2 \mathrm{dBi}$ (from 15 to $18.2 \mathrm{dBi}$ ) and the $-3 \mathrm{~dB}$ directivity bandwidth raises from $8.4 \%$ to $13 \%$.

\subsubsection{Simulated results of the final structure}

Figure 14 represents the radiation pattern in the vertical $(\mathrm{H})$ and horizontal (E) planes of the antenna.

The antenna is directive in the H-plane and sectoral in the E-plane $\left(63^{\circ}\right)$. The maximum directivity reaches $18.2 \mathrm{dBi}$. The patterns have low side lobes, so we can estimate that the structure is well dimensioned.

The return loss shown in Figure 15 is satisfying, as it remains lower than $-10 \mathrm{~dB}$ on the whole band.

\subsection{Antenna in vertical polarization}

This new antenna uses only a one-dimensional structure in TM polarization; the feed ports and the metallic rods must be in a vertical distribution (Figure 16).

The metallic EBG structure in TM polarization is made of 3 square rods $10 \mathrm{~mm}$ wide, the periodicity being $p=$ $60.5 \mathrm{~mm}$. The four metallic rods, $10 \mathrm{~mm}$ wide, on the side of the antenna are used in place of a PEC. The simulated ground plane has the same size as the structure, that is, $1200 * 164 \mathrm{~mm}^{2}$. The cavity height will be determined by the following relation (4), where the phases correspond to the reflection coefficient of the walls defining the cavity:

$$
h=\frac{1}{2} \cdot \frac{c \cdot\left(1 / 2+\angle_{E B G} / 360\right)}{\sqrt{f^{2}-\left(c^{2} / 4 \cdot l^{2}\right) \cdot\left(\angle_{\text {Walls }} / 180\right)^{2}}},
$$

with $l$ the antenna width.

The EBG structure is thus situated at $80 \mathrm{~mm}$ over the ground plane, which is about $\lambda_{0} / 2$. Its operating frequency is around $1.95 \mathrm{GHz}$.

The influence of the different parameters such as the multisource technique and the filling ratio is the same as for 


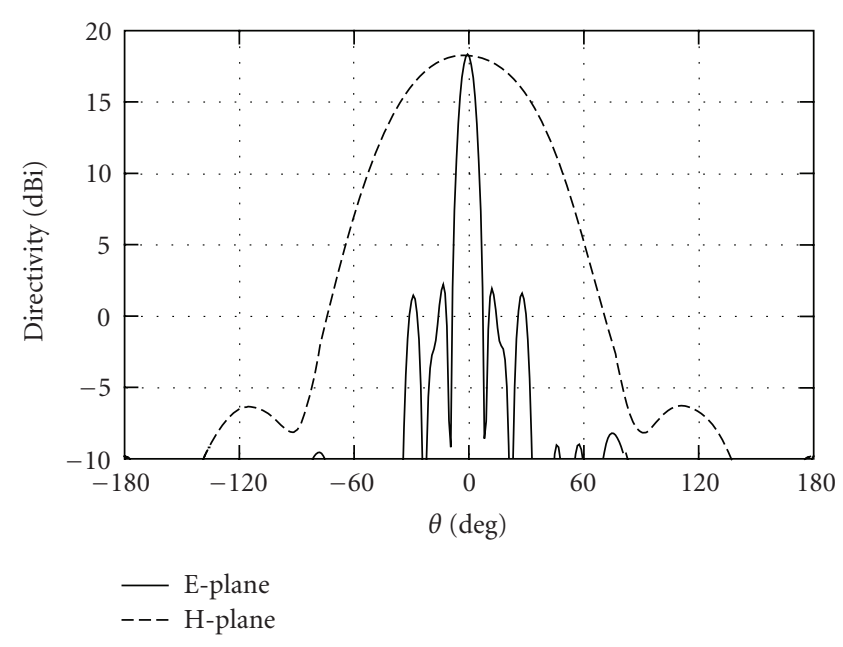

FIGURE 17: Radiation patterns at $1.97 \mathrm{GHz}$.

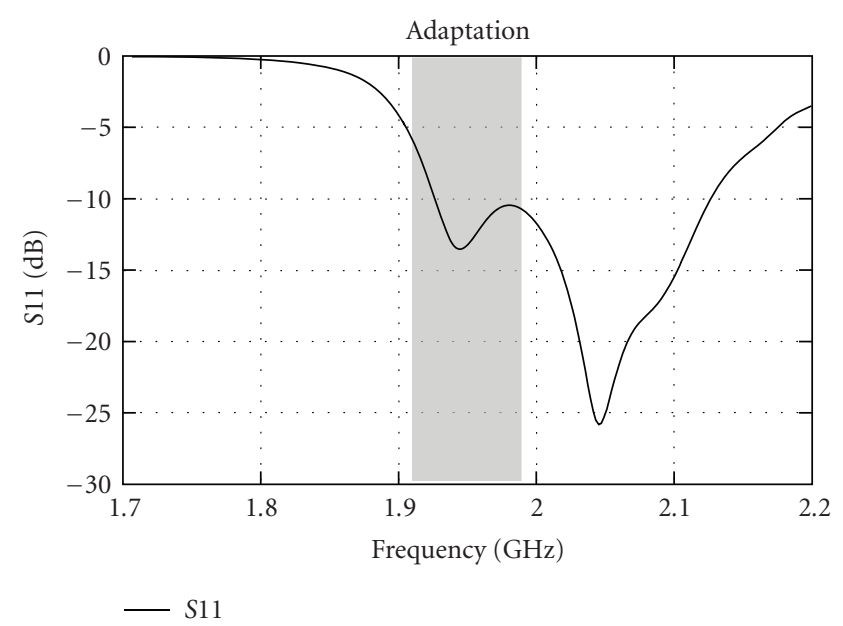

FIgURE 18: Return loss.

the last antenna. This antenna offers a significant directivity reaching more than $18 \mathrm{dBi}$ and a very good sectoral cover in the azimuth plane.

Figure 17 represents the radiation patterns at $1.97 \mathrm{GHz}$; we obtain a radiation beamwidth in the $\mathrm{H}$ plane of $65^{\circ}$ and a very directive pattern in the $\mathrm{E}$ plane. Maximum directivity reaches $18.3 \mathrm{dBi}$. The side lobes are correct, being lower than $-16 \mathrm{~dB}$ compared to the main lobe in the E plane.

The return loss showed in Figure 18 is very correct.

\section{CONCLUSION}

We showed in this paper how EBG antennas are able to radiate with a sectoral pattern, both in vertical and horizontal polarizations. The half-power beamwidth obtained is greater than $60^{\circ}$ in the azimuthal plane and can be increased to more than $90^{\circ}$ but with a lower directivity.

Moreover, the use of the multisource technique enabled us to increase the gain and the bandwidth at the same time, reaching the interesting performances of $18 \mathrm{dBi}$ directivity with a $13 \%$ bandwidth, while conserving a $60^{\circ}$ beamwidth.
It is also possible, by combining the last two structures independently designed, to obtain an antenna operating in both polarizations with a sectoral pattern in azimuth. Such an antenna can be used to radiate in circular polarization [12].

\section{REFERENCES}

[1] E. Yablonovitch, "Photonic band-gap structures," Journal of the Optical Society of America B, vol. 10, no. 2, pp. 283-295, 1993.

[2] G. V. Trentini, "Partially reflecting sheet arrays," IEEE Transactions on Antennas and Propagation, vol. 4, no. 4, pp. 666-671, 1956.

[3] M. Thèvenot, C. Cheype, A. Reineix, and B. Jecko, "Directive photonic-bandgap antennas," IEEE Transactions on Microwave Theory and Techniques, vol. 47, no. 11, pp. 2115-2122, 1999.

[4] C. Cheype, C. Serier, M. Thèvenot, T. Monédière, A. Reineix, and B. Jecko, "An electromagnetic bandgap resonator antenna," IEEE Transactions on Antennas and Propagation, vol. 50, no. 9, pp. 1285-1290, 2002.

[5] D. R. Jackson and N. G. Alexopoulos, "Gain enhancement methods for printed circuit antennas," IEEE Transactions on Antennas and Propagation, vol. 33, no. 9, pp. 976-987, 1985.

[6] M. Qiu and S. He, "High-directivity patch antenna with both photonic bandgap substrate and photonic bandgap cover," Microwave and Optical Technology Letters, vol. 30, no. 1, pp. 41-44, 2001.

[7] L. Freytag, E. Pointereau, and B. Jecko, "Omnidirectional dielectric electromagnetic band gap antenna for base station of wireless network," in Proceedings of IEEE AP-S International Symposium and USNC/URSI National Radio Science Meeting, vol. 1, pp. 815-818, Monterey, Calif, USA, June 2004.

[8] H. Chreim, E. Pointereau, P. Dufrane, and B. Jecko, "Metallic EBG antenna with omnidirectional pattern in the azimuth for base station applications," in Proceedings of the European Conference on Antennas and Propagation (EuCAP '06), vol. 626, p. 438, Nice, France, November 2006.

[9] K. Kohrt, "On the road to UMTS: through GSM, GPRS and EDGE," Wireless Europe, May 2002.

[10] R. Gardelli, M. Albani, and F. Capolino, "Array thinning by using antennas in a Fabry-Perot cavity for gain enhancement," IEEE Transactions on Antennas and Propagation, vol. 54, no. 7, pp. 1979-1990, 2006.

[11] L. Leger, T. Monédière, M. Thèvenot, and B. Jecko, "Methodology to design high gain EBG antennas. Enhancement of gain and bandwidth," in Proceedings of the Progress in Electromagnetics Research Symposium (PIERS '04), Pisa, Italy, March 2004.

[12] M. Diblanc, E. Rodes, E. Arnaud, M. Thèvenot, T. Monédière, and B. Jecko, "Circularly polarized metallic EBG antenna," IEEE Microwave and Wireless Components Letters, vol. 15, no. 10, pp. 638-640, 2005. 

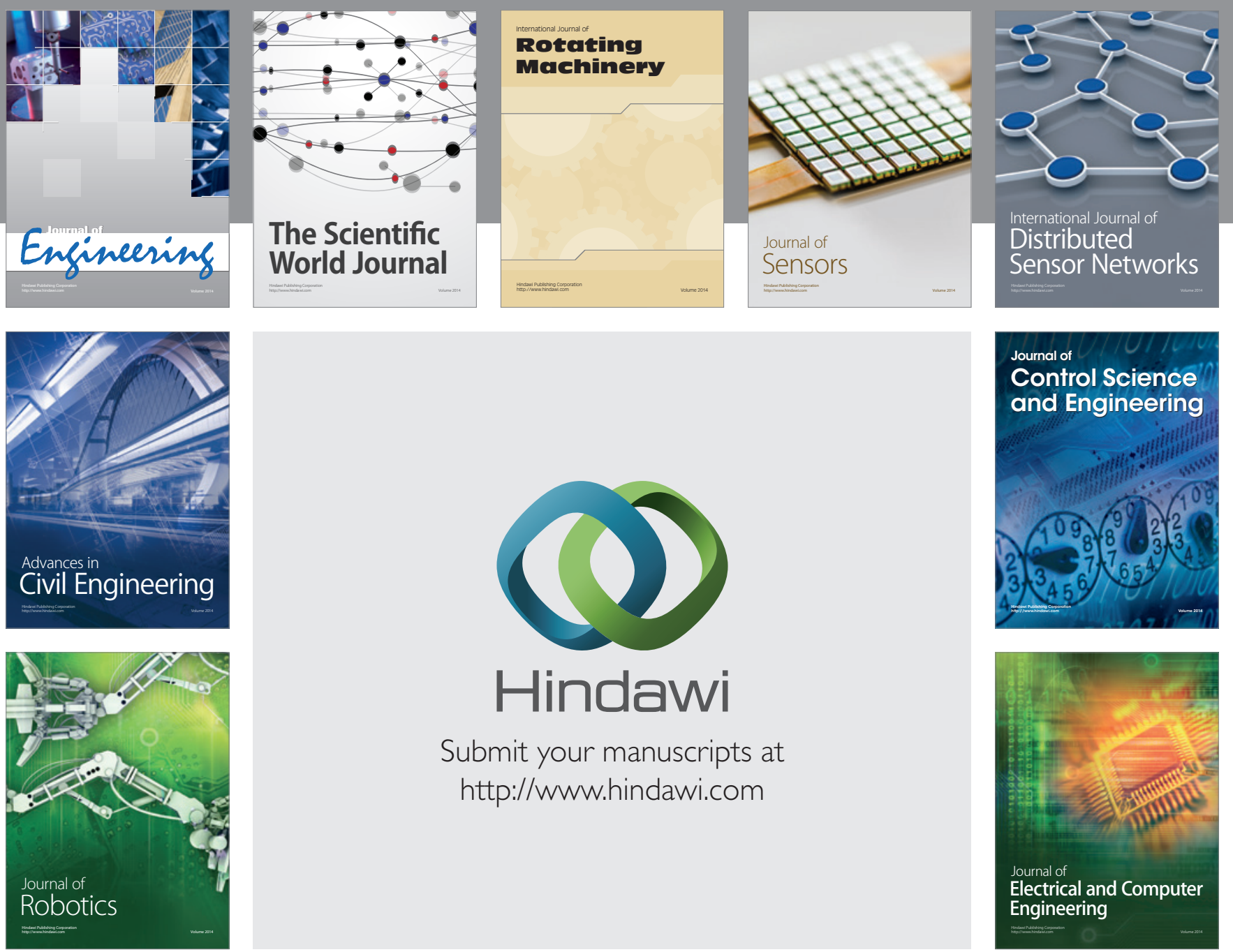

Submit your manuscripts at

http://www.hindawi.com
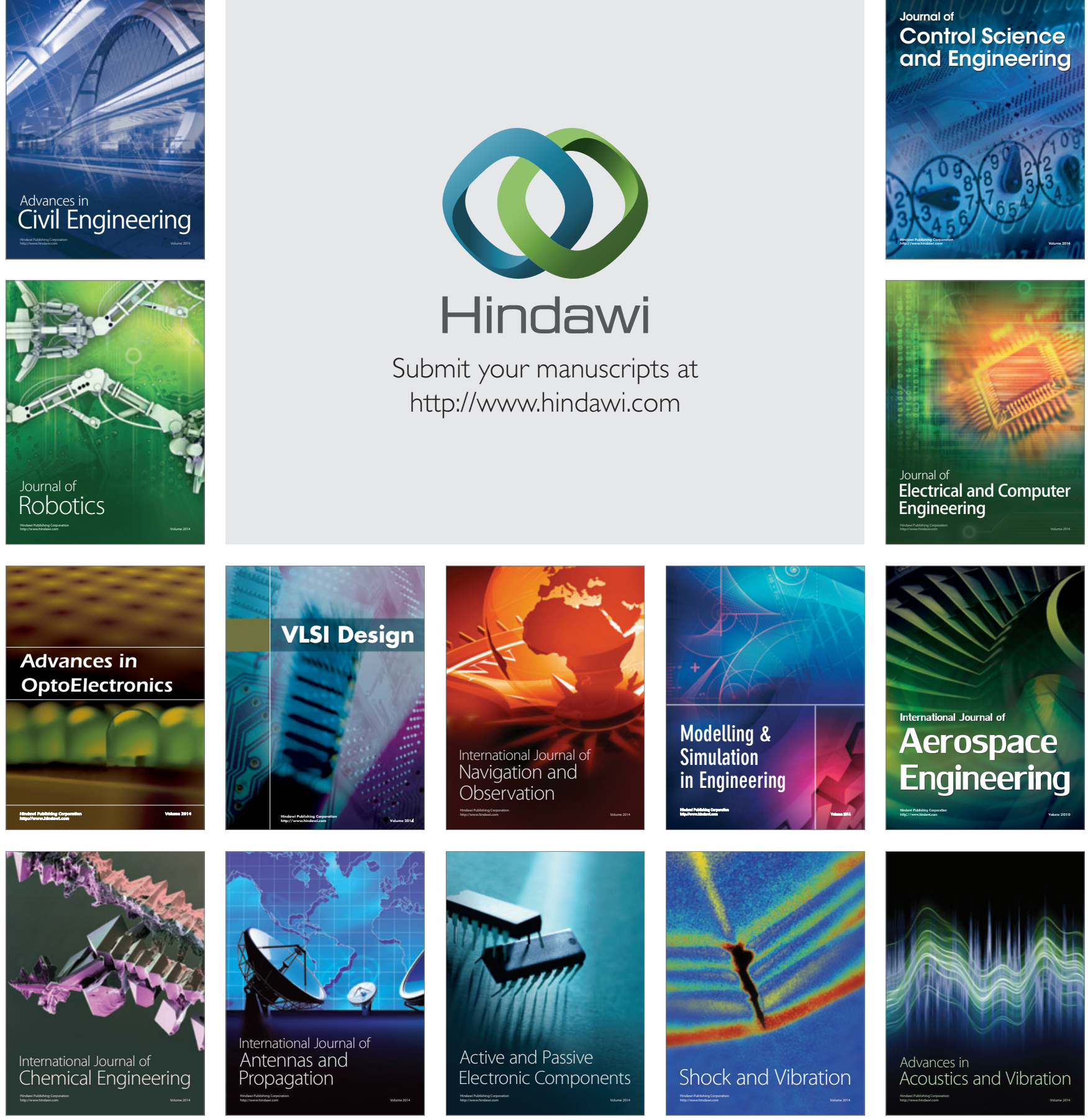